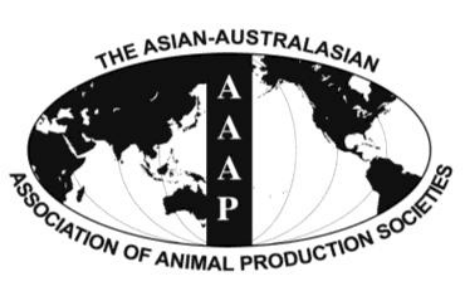

Open Access

Asian Australas. J. Anim. Sci.

Vol. 28, No. 3 : 369-373 March 2015

http://dx.doi.org/10.5713/ajas.14.0539

www.ajas.info

pISSN 1011-2367 elSSN 1976-5517

\title{
Effects of Dietary Cellulose on the Basal Endogenous Loss of Phosphorus in Growing Pigs
}

\author{
A. R. Son and B. G. Kim* \\ Department of Animal Science and Technology, Konkuk University, Seoul 143-701, Korea
}

\begin{abstract}
An experiment was conducted to determine the effect of cellulose concentration in diets containing no phosphorus (P) on the basal endogenous loss (BEL) of $\mathrm{P}$ in growing pigs. Twelve barrows (an initial mean body weight $=49.6 \pm 3.2 \mathrm{~kg}$ ) were individually housed in metabolism crates. Pigs were allotted to 4 experimental diets according to a cross-over design with 12 animals and 2 periods. Four P-free diets were mainly based on corn starch, sucrose, and gelatin, and were formulated to contain $0 \%, 4 \%, 8 \%$, or $12 \%$ cellulose. Each period consisted of a 5-d adaptation and a 5-d collection period. The marker-to-marker method was used for fecal collection. The feed intake $(p<0.05$, linear and quadratic) and dry feces output $(p<0.01$, linear and quadratic) were increased with increasing dietary cellulose concentration. However, $\mathrm{P}$ concentration in the feces was decreased $(\mathrm{p}<0.01$, linear and quadratic) with increasing dietary cellulose concentration. There was no significant difference in total P output and the BEL of P as mg per kg DMI (ranging from 157 to $214 \mathrm{mg} / \mathrm{kg}$ of dry matter intake) among experimental diets. However, values for the apparent total tract digestibility of energy, dry matter, organic matter, crude protein, and calcium were linearly decreased $(p<0.01)$ with increasing cellulose concentration in the diet. In conclusion, dietary cellulose affected the amount of feces and digestibility of energy and nutrients, but did not affect the endogenous loss of P. (Key Words: Digestibility, Endogenous Excretion, Fiber, Phosphorus, Swine)
\end{abstract}

\section{INTRODUCTION}

The standardized total tract digestibility (STTD) is more accurate than the apparent total tract digestibility (ATTD) for determination of phosphorus (P) availability (Almeida and Stein, 2011; Son et al., 2013). Moreover, the value for STTD of $\mathrm{P}$ is considered more additive than the ATTD in mixed diets (Almeida and Stein, 2010), which enables an accurate formulation swine diets. The ATTD of $\mathrm{P}$ is corrected by the basal endogenous loss (BEL) of $\mathrm{P}$ from pigs fed a P-free diet to calculate the STTD of P (Kim et al., 2012).

In case of nitrogen, an increase of dietary fiber content leads to increase ileal nitrogen losses (Schulze et al., 1994; Gabert et al., 2001). There was a hypothesis that high dietary fiber content may increase endogenous losses of $\mathrm{P}$ (Petersen and Stein, 2006; Son et al., 2013). If the value for

\footnotetext{
* Corresponding Author: B. G. Kim. Tel: +82-2-2049-6255, Fax: +82-446-6255, E-mail: bgkim@konkuk.ac.kr Submitted Jul. 19, 2014; Revised Sept. 5, 2014; Accepted Sept. 13, 2014
}

the BEL of P estimated from the pig fed a P-free diet is affected by the fiber concentration in the diet, the STTD of $\mathrm{P}$ may be largely influenced by dietary fiber. However, the effect of dietary fiber concentration on the endogenous loss of $\mathrm{P}$ has not been documented. Therefore, the objective of this study was to determine the effects of fiber concentration in the $\mathrm{P}$-free diets on the BEL of $\mathrm{P}$ in growing pigs.

\section{MATERIALS AND METHODS}

\section{Animal care}

The experimental procedure was approved by the Institutional Animal Care and Use Committee at Konkuk University.

\section{Animal, diet, and feeding}

Twelve barrows with an initial mean body weight (BW) of $49.6 \mathrm{~kg}$ (standard deviation = 3.2) were used to determine the effects of dietary fiber concentration in the Pfree diet on the BEL of P. Pigs were individually housed in 
metabolic creates equipped with a feeder and a nipple drinker.

Four P-free experimental diets were prepared (Tables 1 and 2). The experimental diets were mainly based on corn starch, sucrose, and gelatin and were formulated to contain $0 \%, 4 \%, 8 \%$, or $12 \%$ cellulose (Comprecel, Mingtai Chemical Co., LTD, Bah-Der, Taiwan). The inclusion rate of cellulose was decided based on the values in the literature (Almeida and Stein, 2011; Kim et al., 2012; Son et al., 2013). Vitamins and minerals were adequate to meet or exceed requirement estimates of NRC (1998).

The pigs were allotted to 4 dietary treatments in a crossover design with 12 animals and 2 periods. The amount of daily feed allowance per pig was calculated as approximately 2.5 times the estimated energy requirement for maintenance (i.e., $106 \mathrm{kcal}$ of metabolizable energy $[\mathrm{ME}] / \mathrm{kg}$ of $\mathrm{BW}^{0.75}$; NRC, 1998). The daily feed allowance divided into 2 equal meals, and fed to pigs at 0800 and 1600 . At the beginning of each period, the BW of pigs was measured to determine the daily feed allowance. Water was available at all times. Considering the potential problems in pigs fed the $\mathrm{P}$ deficient diet for a long time, a commercial corn-soybean meal-based diet was fed to the pigs for $7 \mathrm{~d}$ between the 2 periods.

\section{Sample collection}

Each experimental period consisted of a 5-d adaptation

Table 1. Ingredient composition of experimental diets, as-fed basis

\begin{tabular}{lcccc}
\hline \multirow{2}{*}{ Ingredient (\%) } & \multicolumn{4}{c}{ Dietary cellulose concentration $(\%)$} \\
\cline { 2 - 5 } & 0 & 4 & 8 & 12 \\
\hline Corn starch & 55.19 & 51.19 & 47.19 & 43.19 \\
Sucrose & 20.00 & 20.00 & 20.00 & 20.00 \\
Gelatin & 17.00 & 17.00 & 17.00 & 17.00 \\
Soybean oil & 4.70 & 4.70 & 4.70 & 4.70 \\
Cellulose $^{1}$ & - & 4.00 & 8.00 & 12.00 \\
DL-methionine & 0.30 & 0.30 & 0.30 & 0.30 \\
L-threonine & 0.10 & 0.10 & 0.10 & 0.10 \\
L-tryptophan & 0.11 & 0.11 & 0.11 & 0.11 \\
L-histidine & 0.10 & 0.10 & 0.10 & 0.10 \\
L-isoleucine & 0.10 & 0.10 & 0.10 & 0.10 \\
Ground limestone & 1.00 & 1.00 & 1.00 & 1.00 \\
Potassium carbonate & 0.40 & 0.40 & 0.40 & 0.40 \\
Magnesium oxide & 0.10 & 0.10 & 0.10 & 0.10 \\
Salt & 0.40 & 0.40 & 0.40 & 0.40 \\
Vitamin-mineral premix $^{2}$ & 0.50 & 0.50 & 0.50 & 0.50 \\
\hline
\end{tabular}

${ }^{1}$ Comprecel (Mingtai Chemical Co., LTD, Bah-Der, Taiwan).

${ }^{2}$ Provided the following quantities per $\mathrm{kg}$ of complete diet: vitamin A, 25,000 IU; vitamin $\mathrm{D}_{3}, 4,000 \mathrm{IU}$; vitamin E, $50 \mathrm{IU}$; vitamin $\mathrm{K}, 5.0 \mathrm{mg}$; thiamin, $4.9 \mathrm{mg}$; riboflavin, $10.0 \mathrm{mg}$; pyridoxine, $4.9 \mathrm{mg}$; vitamin $\mathrm{B}_{12}$, $0.06 \mathrm{mg}$; pantothenic acid, $37.5 \mathrm{mg}$; folic acid, $1.10 \mathrm{mg}$; niacin, $62 \mathrm{mg}$; biotin, $0.06 \mathrm{mg}$; $\mathrm{Cu}, 25 \mathrm{mg}$ as copper sulfate; $\mathrm{Fe}, 268 \mathrm{mg}$ as iron sulfate; I, $5.0 \mathrm{mg}$ as potassium iodate; $\mathrm{Mn}, 125 \mathrm{mg}$ as manganese sulfate; Se, $0.38 \mathrm{mg}$ as sodium selenite; $\mathrm{Zn}, 313 \mathrm{mg}$ as zinc oxide; butylated hydroxytoluene, $50 \mathrm{mg}$. and 5-d collection period. A total amount of feces was collected according to a marker-to-marker procedure (Kong and Adeola, 2014). Chromium oxide was added at $0.5 \%$ to the morning meal as an indigestible marker on $\mathrm{d} 6$ and 11 in each period. Fecal collection was started when the color of marker begin to appear in the feces, and ended when the color appeared again. Collected fecal samples were immediately stored at $-20^{\circ} \mathrm{C}$ in the freezer until subsequent chemical analyses.

\section{Chemical analysis}

The total amount of feces samples was dried in a forcedair drying oven at $55^{\circ} \mathrm{C}$ and then ground for analyses. Diet and feces samples were dried in the forced-air drying oven at $135^{\circ} \mathrm{C}$ for $2 \mathrm{~h}$ to analyze dry matter (DM; method 930.15; AOAC, 2005). Diet and feces samples were analyzed for gross energy (Parr 1261 bomb calorimeter; Parr Instruments Co., Moline, IL, USA), crude protein (CP; method 990.03; AOAC, 2005), ether extract (EE; method 920.39; AOAC, 2005), and ash (method 942.05; AOAC, 2005). Calcium (Ca) in diet and feces samples was analyzed (method 978.02; AOAC, 2005) using an atomic absorption spectrophotometer (Perkin Elmer 3300, Perkin Elmer, Akron, OH, USA). Diet samples were also analyzed for crude fiber (method 978.10; AOAC 2005), neutral detergent fiber (NDF; Goering and van Soest, 1970), and acid detergent fiber (method 973.18; AOAC, 2005). Phosphorus in feces samples was analyzed (method 946.06; AOAC, 2005) using a spectrophotometer (Optizen 2120UV, Mecasys, Daejeon, Korea).

\section{Statistical analysis}

Data were analyzed using the MIXED procedure of SAS (SAS Inst. Inc., Cary, NC, USA). Two outliers (difference from median $>2 \times$ interquartile range) were identified in 2 experimental diets, and were removed from the final data set. The model included dietary treatment as a

Table 2. Chemical composition of experimental diets ${ }^{1}$, as-fed basis

\begin{tabular}{lcccc}
\hline \multirow{2}{*}{ Item } & \multicolumn{4}{c}{ Dietary cellulose concentration (\%) } \\
\cline { 2 - 5 } & 0 & 4 & 8 & 12 \\
\hline Dry matter (\%) & 91.0 & 91.2 & 91.8 & 92.1 \\
Gross energy (kcal/kg) & 4,091 & 4,086 & 4,098 & 4,090 \\
Metabolizable energy $^{2}$ & 3,717 & 3,558 & 3,398 & 3,239 \\
$\quad$ (kcal/kg) & & & & \\
Crude protein (\%) & 18.6 & 19.1 & 18.5 & 17.5 \\
Ether extract (\%) & 4.31 & 4.60 & 4.84 & 4.64 \\
Ash (\%) & 2.77 & 3.64 & 3.14 & 3.74 \\
Calcium (\%) & 0.51 & 0.55 & 0.52 & 0.50 \\
Neutral detergent fiber (\%) & 3.55 & 7.33 & 10.1 & 13.5 \\
Acid detergent fiber (\%) & 0.76 & 3.36 & 4.83 & 10.9 \\
\hline
\end{tabular}

${ }^{1}$ Data are the mean of duplicate analyses of each diet

${ }^{2}$ Values are calculated based on NRC (1998) for each ingredient. 
Table 3. Feed intake, fecal output, and the basal endogenous loss (BEL) of phosphorus (P) in growing pigs fed the P-free diets with $0 \%$ to $12 \%$ of cellulose

\begin{tabular}{|c|c|c|c|c|c|c|c|}
\hline \multirow{2}{*}{ Item $^{1}$} & \multicolumn{4}{|c|}{ Dietary cellulose concentration (\%) } & \multirow{2}{*}{ SEM } & \multicolumn{2}{|c|}{$\mathrm{p}$-value } \\
\hline & 0 & 4 & 8 & 12 & & Linear & Quadratic \\
\hline Observation (n) & 5 & 6 & 6 & 5 & & & \\
\hline Feed intake $(\mathrm{g} / \mathrm{d})$ & 1,145 & 1,509 & 1,576 & 1,444 & 165 & 0.012 & 0.038 \\
\hline $\mathrm{DMI}(\mathrm{g} / \mathrm{d})$ & 1,041 & 1,377 & 1,446 & 1,331 & 150 & 0.010 & 0.039 \\
\hline \multicolumn{8}{|l|}{ Dried fecal output } \\
\hline Total fecal output (g/d) & 16.2 & 82.8 & 40.5 & 160.1 & 9.6 & $<0.001$ & 0.007 \\
\hline Fecal output (g/kg DMI) & 16.0 & 60.8 & 96.5 & 119.9 & 3.4 & $<0.001$ & 0.013 \\
\hline $\mathrm{P}$ in feces $(\%)$ & 1.28 & 0.30 & 0.17 & 0.17 & 0.06 & $<0.001$ & $<0.001$ \\
\hline Total P output (g/d) & 0.219 & 0.246 & 0.225 & 0.233 & 0.022 & 0.806 & 0.643 \\
\hline BEL of P (mg/kg DMI) & 214 & 184 & 157 & 185 & 32 & 0.173 & 0.152 \\
\hline
\end{tabular}

SEM, standard error of the means; DMI, dry matter intake.

${ }^{1}$ Values for feed intake, total fecal output, $\mathrm{P}$ in feces, and total $\mathrm{P}$ output were represented based on as-fed basis.

fixed variable and replication, animal within replication, and period as random variables. Orthogonal polynomial contrasts were used to test linear and quadratic responses of treatment. Least squares means of each treatment were calculated. The experimental unit was a pig, and an alpha level of 0.05 was used to test the statistical significance.

\section{RESULTS}

There were no health problems observed in the pigs during the experimental period. Daily feed intake and dry matter intake (DMI) were linearly and quadratically increased $(p<0.05)$ with increasing dietary cellulose concentration (Table 3). Daily total fecal output was linearly and quadratically increased $(\mathrm{p}<0.01)$ with increasing dietary cellulose concentration. The fecal output per kg DMI were also linearly and quadratically increased $(\mathrm{p}<0.05)$ with increasing dietary cellulose concentration. However, the $\mathrm{P}$ concentration in the feces was decreased $(p<0.01)$ with increasing dietary cellulose concentration. There were no differences in the total $\mathrm{P}$ output and the BEL of $\mathrm{P}$ as mg per kg DMI among experimental diets.

The energy concentration in the feces was not different among experimental diets (Table 4). The DM concentration in the feces was linearly increased $(p<0.05)$ with increasing dietary cellulose concentration. The organic matter (OM), $\mathrm{CP}, \mathrm{EE}$, and $\mathrm{Ca}$ concentrations in the feces were linearly and quadratically increased $(\mathrm{p}<0.01)$ with increasing dietary cellulose concentration.

The ATTD of energy and CP were linearly decreased $(p<0.01)$ with increasing dietary cellulose concentration. The ATTD of DM, OM, and $\mathrm{Ca}$ were linearly and quadratically decreased $(\mathrm{p}<0.05)$ with increasing dietary cellulose concentration. However, there was no difference

Table 4. Energy and nutrients concentrations in the feces and the apparent total tract digestibility (ATTD) of energy and nutrients in the phosphorus-free diets with $0 \%$ to $12 \%$ of cellulose fed to growing pigs, as-fed basis

\begin{tabular}{|c|c|c|c|c|c|c|c|}
\hline \multirow{2}{*}{ Item } & \multicolumn{4}{|c|}{ Dietary cellulose concentration (\%) } & \multirow{2}{*}{ SEM } & \multicolumn{2}{|c|}{ p-value } \\
\hline & 0 & 4 & 8 & 12 & & Linear & Quadratic \\
\hline Observation (n) & 5 & 6 & 6 & 5 & & & \\
\hline \multicolumn{8}{|c|}{ Concentration in feces (\%) } \\
\hline Energy (kcal/kg) & 3,971 & 3,771 & 3,816 & 3,914 & 89 & 0.691 & 0.079 \\
\hline Dry matter & 94.1 & 95.5 & 96.0 & 96.2 & 1.2 & 0.030 & 0.375 \\
\hline Organic matter & 61.2 & 81.2 & 86.7 & 89.2 & 1.0 & $<0.001$ & $<0.001$ \\
\hline Crude protein & 16.8 & 6.76 & 4.75 & 5.28 & 0.97 & $<0.001$ & $<0.001$ \\
\hline Ether extract & 3.73 & 1.02 & 0.66 & 0.70 & 0.15 & $<0.001$ & $<0.001$ \\
\hline Calcium & 7.53 & 3.74 & 2.52 & 1.92 & 0.37 & $<0.001$ & 0.001 \\
\hline \multicolumn{8}{|l|}{ ATTD (\%) } \\
\hline Energy & 98.6 & 94.9 & 91.9 & 89.7 & 0.3 & $<0.001$ & 0.073 \\
\hline Dry matter & 98.5 & 94.2 & 90.7 & 88.4 & 0.4 & $<0.001$ & 0.022 \\
\hline Organic matter & 99.0 & 94.9 & 91.3 & 88.8 & 0.3 & $<0.001$ & 0.045 \\
\hline Crude protein & 98.6 & 98.0 & 97.7 & 96.7 & 0.3 & $<0.001$ & 0.360 \\
\hline Ether extract & 98.7 & 98.8 & 98.8 & 98.3 & 0.2 & 0.114 & 0.126 \\
\hline Calcium & 78.4 & 62.8 & 57.1 & 58.2 & 2.4 & $<0.001$ & 0.015 \\
\hline
\end{tabular}

SEM, standard error of the means. 
in the ATTD of EE among the experimental diets.

\section{DISCUSSION}

Cellulose has been often used as a fiber source in a Pfree diet in previous experiments (Almeida and Stein, 2011; Kim et al., 2012; Son et al., 2013). The influence of dietary fiber on nutrient utilization (Ravindran et al., 1984; Wilfart et al., 2007) and endogenous nitrogen excretion (Schulze et al., 1994; Yin et al., 2000) has been documented. To the best of our knowledge, the present experiment first addresses the effects of graded concentrations of dietary cellulose on the BEL of $\mathrm{P}$ in pigs.

The differences of the NDF concentration among experimental diets were similar to the intended differences when the diets were formulated with graded concentrations of cellulose in the present work. The NDF concentration in the purified diet without cellulose was analyzed to be $3.55 \%$, which may be due to the small quantities of NDF in corn starch, sucrose, and gelatin.

In this study, we tried to synchronize ME intake among the treatment groups and the daily feed allowance was calculated based on the $\mathrm{BW}$ and the ME concentration of each experimental diet. The daily feed allowance was increased with increasing dietary fiber concentration because calculated ME concentrations in the experimental diets decreased with increasing dietary fiber concentration (Table 2). Therefore, the differences in the feed intake were expected results.

Dietary fiber did not affect the total P output or the BEL of $\mathrm{P}$. The fecal output was increased, but the $\mathrm{P}$ concentration in the feces was decreased with increasing dietary cellulose concentration. This subsequently caused insignificant differences of the P output and the BEL of P regardless of dietary cellulose concentration. The reason why we failed to find the effect of dietary cellulose on endogenous $\mathrm{P}$ excretion was likely associated with the structure of the cellulose source. The cellulose source used in this experiment was a microcrystalline cellulose product which was partially depolymerized cellulose from purified wood pulp and thus had perhaps a minimal physical influence on sloughing of intestinal cells. This theory is well supported by previous studies that measured ileal endogenous excretions of nitrogen by feeding various sources of fiber. Schulze et al. (1994) suggested that purified NDF induced an increased excretion of endogenous ileal nitrogen at least partially due to the intact fibrous structure of the purified NDF. However, purified wood cellulose in nitrogen-free diets did not influence the ileal amino acids or nitrogen excretion (Furuya and Kaji, 1992) which was similar to the present endogenous $\mathrm{P}$ results. Physical or chemical properties of dietary fiber may be a more critical factor for ileal endogenous nitrogen excretion than the concentration of dietary fiber (Leterme et al., 1996; Souffrant, 2001; Libao-Mercado et al., 2006; Park et al., 2013).

The decreased ATTD of energy, DM, and OM with increasing dietary fiber concentration in this experiment was likely due to the very low concentration of digestible carbohydrates in the cellulose which was added at the expense of corn starch. Another reason may be an increased passage rate with increasing dietary cellulose concentration. While the time for marker appearance in feces after feeding was 2 to 4 days in pigs fed $4 \%, 8 \%$, or $12 \%$ cellulose diets, it was at least 7 days in pigs fed a $0 \%$ cellulose diet (data not shown). A fast passage rate of digesta due to high dietary fiber concentrations was associated with low digestibility of energy and nutrients (Ravindran et al., 1984), which coincided with the present results. Moreover, a slower passage rate resulted in a higher DM digestibility in pigs, which was independent of dietary fiber concentration (Kim et al., 2007).

The decreased nutrient digestibility with increasing dietary fiber concentration in the present study was consistent with data in the literature (Kass et al., 1980; Ravindran et al., 1984; Le Goff et al., 2002). Although the possible influence of feed intake on the nutrient digestibility should not be neglected, the extent of feed intake variation would not largely affect the nutrient digestibility (Moter and Stein, 2004). Another factor affecting the nutrient digestibility was the initial $\mathrm{BW}$, but the relatively narrow range of initial BW (from 44.2 to $56.4 \mathrm{~kg}$ ) would not be the reason for the different DM digestibility (Kim et al., 2007).

In contrast to energy, OM, and DM, the ATTD of EE was not affected by dietary cellulose concentration. Generally, extracted free-form oil sources are very easily digested and absorbed in the small intestine compared with intact-form oil sources (Kim et al., 2013). Soybean oil, a free-form source, mostly contributed to the dietary EE in this experiment. The time of digesta retention in the intestinal tract was likely sufficient for the efficient digestion and absorption of the free-form oil.

\section{CONCLUSION}

The ATTD of energy, DM, OM, and other nutrients decreases with increasing dietary microcrystalline cellulose concentration. However, the microcrystalline cellulose did not affect the endogenous loss of P. Further studies to test the effects of a crude type of cellulose and different sources of dietary fiber on the endogenous excretion of $\mathrm{P}$ are warranted in the future.

\section{ACKNOWLEDGMENTS}

This study resulted from the Konkuk University research support program. 


\section{REFERENCES}

Almeida, F. N. and H. H. Stein. 2010. Performance and phosphorus balance of pigs fed diets formulated on the basis of values for standardized total tract digestibility of phosphorus. J. Anim. Sci. 88:2968-2977.

Almeida, F. N. and H. H. Stein. 2011. Standardized total tract digestibility of phosphorus in blood products fed to weanling pigs. Rev. Colomb. Cienc. Pecu. 24:617-622.

AOAC. 2005. Official Methods of Analysis, 18th edn. Association of Official Analytical Chemists, Arlington, VA, USA.

Furuya, S. and Y. Kaji. 1992. The effects of feed intake and purified cellulose on the endogenous ileal amino acid flow in growing pigs. Br. J. Nutr. 68:463-472.

Gabert, V. M., H. Jorgensen, and C. M. Nyachoti. 2001. Bioavailability of AA in feedstuffs for swine. In: Swine Nutrition (Eds. A. J. Lewis and L. L. Southern) CRC Press, Washington, DC, USA. pp. 151-186.

Goering, H. K. and P. J. van Soest. 1970. Forage fiber analysis (apparatus, reagents, procedures and some applications). Agriculture Handbook No. 379. ARS, USDA, Washington, DC, USA.

Kass, M. L., P. J. van Soest, W. G. Pond, B. Lewis, and R. E. McDowell. 1980. Utilization of dietary fiber from alfalfa by growing swine. I. Apparent digestibility of diet components in specific segments of the gastrointestinal tract. J. Anim. Sci. 50:175-191.

Kim, B. G., M. D. Lindemann, G. L. Cromwell, A. Balfagon, and J. H. Agudelo. 2007. The correlation between passage rate of digesta and dry matter digestibility in various stages of swine. Livest. Sci. 109:81-84.

Kim, B. G., J. W. Lee, and H. H. Stein. 2012. Energy concentration and phosphorus digestibility in whey powder, whey permeate, and low-ash whey permeate fed to weanling pigs. J. Anim. Sci. 90:289-295.

Kim, B. G., D. Y. Kil, and H. H. Stein. 2013. In growing pigs, the true ileal and total tract digestibility of acid hydrolyzed ether extract in extracted corn oil is greater than in intact sources of corn oil or soybean oil. J. Anim. Sci. 91:755-763.

Kong, C. and O. Adeola. 2014. Evaluation of amino acid and energy utilization in feedstuff for swine and poultry diets. Asian Australas. J. Anim. Sci. 27:917-925.

Le Goff, G., S. Dubois, J. van Milgen, and J. Noblet. 2002. Influence of dietary fibre level on digestive and metabolic utilization of energy in growing and finishing pigs. Anim. Res. 51:245-259.
Leterme, P., T. Monmart, A. Thewis, and P. Morandi. 1996. Effect of oral and parenteral $\mathrm{N}$ nutrition vs $\mathrm{N}$-free nutrition on the endogenous amino acid flow at the ileum of the pig. J. Sci. Food Agric. 71:265-271.

Libao-Mercado, A. J., Y. Yin, J. van Eys, and C. F. M. de Lange. 2006. True ileal amino acid digestibility and endogenous ileal amino acid losses in growing pigs fed wheat shorts- or caseinbased diets. J. Anim. Sci. 84:1351-1361.

Moter, V. and H. H. Stein. 2004. Effect of feed intake on endogenous losses and amino acid and energy digestibility by growing pigs. J. Anim. Sci. 82:3518-3525.

National Research Council. 1998. Nutrient Requirements of Swine. 10th Ed. National Academy Press, Washington, DC, USA.

Park, C. S., S. I. Oh, and B. G. Kim. 2013. Prediction of basal endogenous losses of amino acids based on body weight and feed intake in pigs fed nitrogen-free diets. Rev. Colomb. Cienc. Pecu. 26:186-192.

Petersen, G. I. and H. H. Stein. 2006. Novel procedure for estimating endogenous losses and measurement of apparent and true digestibility of phosphorus by growing pigs. J. Anim. Sci. 84:2126-2132.

Ravindran, V., E. T. Kornegay, and K. E. Webb, Jr. 1984. Effects of fiber and virginiamycin on nutrient absorption, nutrient retention and rate of passage in growing swine. J. Anim. Sci. 59:400-408.

Schulze, H., P. van Leeuwen, M. W. Verstegen, J. Huisman, W. B. Souffrant, and F. Ahrens. 1994. Effect of level of dietary neutral detergent fiber on ileal apparent digestibility and ileal nitrogen losses in pigs. J. Anim. Sci. 72:2362-2368.

Son, A. R., S. Y. Shin, and B. G. Kim. 2013. Standardized total tract digestibility of phosphorus in copra expellers, palm kernel expellers, and cassava root fed to growing pigs. Asian Australas. J. Anim. Sci. 26:1609-1613.

Souffrant, W. B. 2001. Effect of dietary fibre on ileal digestibility and endogenous nitrogen losses in the pig. Anim. Feed Sci. Technol. 90:93-102.

Wilfart, A., L. Montagne, P. H. Simmins, J. van Milgen, and J. Noblet. 2007. Sites of nutrient digestion in growing pigs: Effect of dietary fiber. J. Anim. Sci. 85:976-983.

Yin, Y. -L., J. D. G. McEvoy, H. Schulze, U. Hennig, W. -B. Souffrant, and K. J. McCracken. 2000. Apparent digestibility (ileal and overall) of nutrients and endogenous nitrogen losses in growing pigs fed wheat (var. Soissons) or its by-products without or with xylanase supplementation. Livest. Prod. Sci. 62:119-132. 